Marquette University

e-Publications@Marquette

2-10-2017

\title{
Isolation of a Chiral Anthracene Cation Radical: X-Ray Crystallography and Computational Interrogation of its Racemization
}

Mikhail V. Ivanov

Marquette University

Khushabu Thakur

Marquette University

Anshul Bhatnagar

Marquette University

Rajendra Rathore

Marquette University, rajendra.rathore@marquette.edu

Follow this and additional works at: https://epublications.marquette.edu/chem_fac

Part of the Chemistry Commons

\section{Recommended Citation}

Ivanov, Mikhail V.; Thakur, Khushabu; Bhatnagar, Anshul; and Rathore, Rajendra, "Isolation of a Chiral Anthracene Cation Radical: X-Ray Crystallography and Computational Interrogation of its Racemization" (2017). Chemistry Faculty Research and Publications. 915.

https://epublications.marquette.edu/chem_fac/915 
Marquette University

\section{e-Publications@Marquette}

\section{Chemistry Faculty Research and Publications/College of Arts and Sciences}

This paper is NOT THE PUBLISHED VERSION; but the author's final, peer-reviewed manuscript. The published version may be accessed by following the link in the citation below.

Chemical Communications, Vol. 53, No. 18 (2017): 2748-2751. DOI. This article is @ Royal Society of Chemistry and permission has been granted for this version to appear in e-Publications@Marquette. Royal Society of Chemistry does not grant permission for this article to be further copied/distributed or hosted elsewhere without the express permission from Royal Society of Chemistry.

\section{Isolation of a chiral anthracene cation radical: X-ray crystallography and computational interrogation of its racemization}

Maxim V. Ivanov

Marquette University

Khushabu Thakur

Marquette University

Anshul Bhatnagar

Marquette University

Rajendra Rathore

Marquette University

\section{Abstract}

Chiral cation-radical salts hold significant promise as charge-transfer materials, chiroptical switches, and electron-transfer catalysts for enantioselective synthesis. Herein we demonstrate that the readily-available chiral 9,10-diphenyleanthracene derivative (i.e. ${ }^{S}$ ANT) forms a robust cation radical, whose structure was elucidated by X-ray crystallography and DFT calculations. While ${ }^{S}$ ANT was observed to racemize on a timescale $\left(t_{1 / 2}\right)$ of 1.1 hours, a computational conformational search and kinetic analysis of the racemization pathway led 
us to identify a simple methyl substituted ${ }^{S}$ ANT derivative, which does not racemize (racemization $t_{1 / 2} 10^{13}-10^{17}$ years).

\section{Introduction}

There is continuing interest in identifying chiral molecules, which form stable cation radicals for applications in electron-transfer catalysed enantioselective synthetic transformations, $\underline{\underline{1}}$ as chiroptical molecular switches, $\underline{\underline{2}}$ in electro-magneto-chiral anisotropy, $\underline{\underline{3}}$ and for enhancing conducting properties under an applied magnetic field, $\underline{4}$ among others. For example, it was shown for several radical-cation salts that enantiopure materials show enhanced conductivity when compared with the corresponding racemic mixtures owing to the structural disorder. 5,6

Unfortunately, examples of stable enantiopure cation radicals are scarce. $\frac{2,5,6}{}$ As polycyclic aromatic hydrocarbons (PAHs) are best suited for isolation of stable cation radicals, the axially chiral PAHs ${ }^{\underline{7}}$ are ideal candidates for chiral cation-radical salts. For example, Agranat and coworkers $\frac{8,9}{9}$ reported that McMurry coupling of the readily-available dibenzo[b,f]suberone unexpectedly afforded a chiral doubly-bridged 9,10diphenylanthracene in excellent yield (eqn (1)). It was concluded that this reaction produced only chiral 'synanthracene' ( ${ }^{\mathrm{S}} \mathrm{ANT}$ ) isomer as a racemic mixture - not the achiral (meso) 'anti-anthracene' ('ANT). Careful chromatographic separation and racemization studies showed that ${ }^{\mathrm{S} A N T}$ racemizes at ambient temperatures despite an activation barrier of $\sim 23 \mathrm{kcal} \mathrm{mol}^{-1} . \underline{8,9}$

(1)

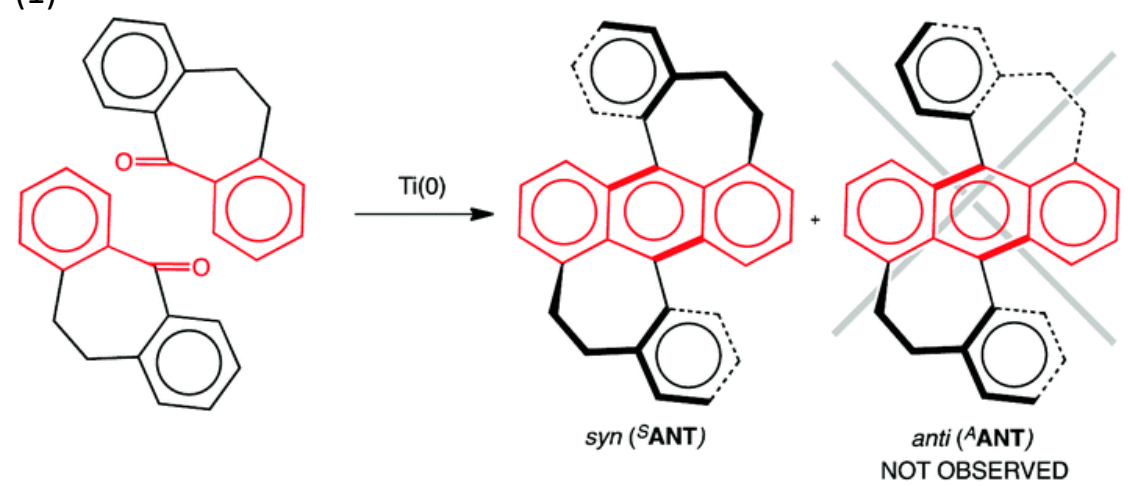

Our continuing interest in design and synthesis of stable cation radicals $\frac{10-15}{15}$ as charge-transport materials for modern photovoltaic applications prompted us to examine if ${ }^{\mathrm{S}} \mathrm{ANT}$ forms a stable cation radical, and whether racemization be prevented by a modification of its structure. In this communication, we will show that this readily available chiral anthracene derivative forms a robust cation-radical salt, which can be isolated and characterized by X-ray crystallography. A detailed conformational analysis of racemization of ${ }^{\mathrm{S}} \mathrm{ANT}$ by DFT calculations and kinetic analysis of racemization led us to design an improved ${ }^{\mathrm{S}} \mathrm{ANT}$ derivative that will not be subject to racemization under ambient conditions. The details of these preliminary findings are described herein.

Initial indication of the stability of the ${ }^{\mathrm{S} A N T}$ cation radical was apparent from completely reversible cyclic voltammograms at scan rates varying from 50 to $400 \mathrm{mV} \mathrm{s}^{-1}$ in dichloromethane (Fig. 1). The measured electrochemical oxidation potential ( $\mathrm{E}_{\mathrm{ox}}=0.46 \mathrm{~V} \mathrm{vs}$. $\mathrm{Fc} / \mathrm{Fc}^{+}$as an added internal standard) ${ }^{\mathrm{S}} \mathrm{ANT}$ was $360 \mathrm{mV}$ lower than 9,10-diphenylanthracene-a non-encumbered analogue of ${ }^{\mathrm{S}} \mathrm{ANT} . \underline{16}$ 


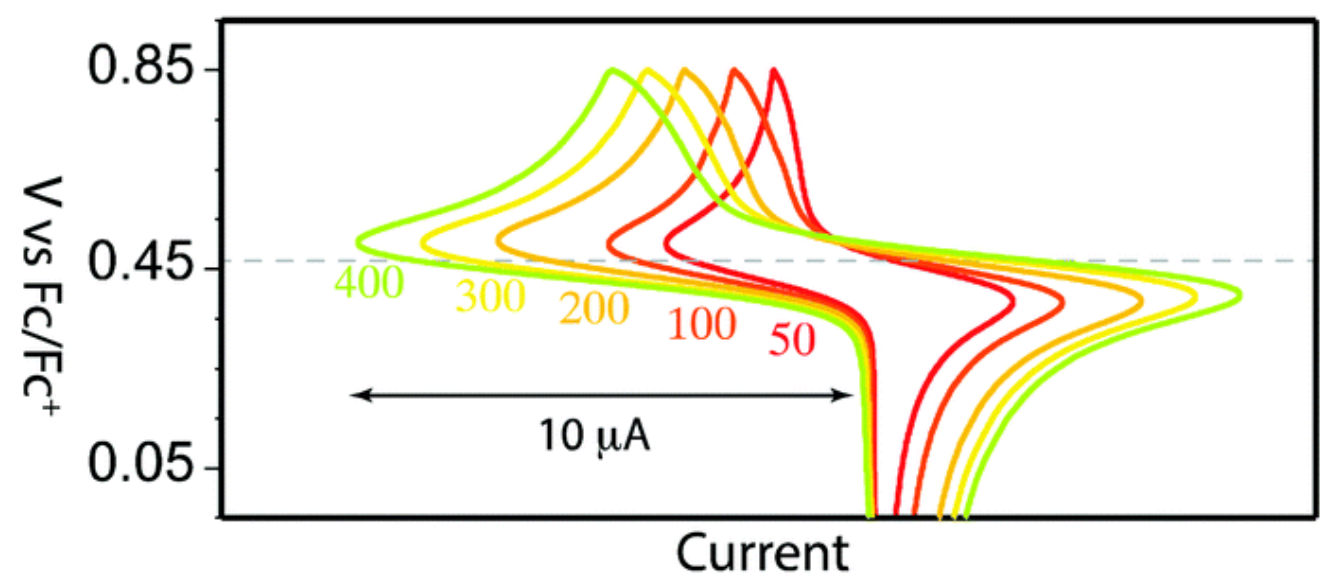

Fig. 1 Cyclic voltammograms of $1 \mathrm{mM}^{\mathrm{s}} \mathrm{ANT}$ at different scan rates (50 to $400 \mathrm{mV}$, as indicated) in $\mathrm{CH}_{2} \mathrm{Cl}_{2}$ containing $0.2 \mathrm{M}$ tetra-n-butylammonium hexafluorophosphate at $22{ }^{\circ} \mathrm{C}$.

The cation radical of ${ }^{\mathrm{A}} \mathrm{ANT}$ can be generated in solution via quantitative redox titrations using $\left[\right.$ THEO $^{+} \mathrm{SbCl}_{6}^{-}$] (THEO = 1,2,3,4,5,6,7,8-octahydro-9,10-dimethoxy-1,4:5,8-dimethano-anthracene, $\mathrm{E}_{\mathrm{red} 1}=$ $0.67 \mathrm{~V}$ vs. $\left.\mathrm{Fc} / \mathrm{Fc}^{+}, \lambda_{\max }=518 \mathrm{~nm}, \varepsilon_{\max }=7300 \mathrm{~cm}^{-1} \mathrm{M}^{-1}\right)$ 至 and [NAP+ ${ }^{-} \mathrm{SbCl}_{6}{ }^{-}$] (NAP = cycloannulated naphthalene derivative, $E_{\text {red } 1}=0.94 \mathrm{~V}$ vs. $\left.F c / F^{+}, \lambda_{\max }=672 \mathrm{~nm}, \varepsilon_{\max }=9300 \mathrm{~cm}^{-1} \mathrm{M}^{-1}\right) \underline{18,19}$ as oxidants. For example, Fig. 2A displays the electronic spectra obtained upon an incremental (sub-stoichiometric) addition of a concentrated $\mathrm{CH}_{2} \mathrm{Cl}_{2}$ solution of ${ }^{\mathrm{A}} \mathrm{ANT}$ to a solution of [ $\mathrm{THEO}^{+} \mathrm{SbCl}_{6}{ }^{-}$] t $22{ }^{\circ} \mathrm{C}$. A complete consumption of the oxidant (i.e.THEO+ ${ }^{+}$) and clean formation of ${ }^{5} \mathbf{A N T}^{+}$, after the addition of 1 equivalent of neutral SANT, was ascertained by a quantitative deconvolution $\underline{20}$ of the component spectra of various species present at each titration point (Fig. 2B). A plot of the mole fractions of various species, obtained from Fig. $2 \mathrm{~B}$, against the added equivalents of ${ }^{\mathrm{S}} \mathrm{ANT}$ established a $1: 1$ stoichiometry of the redox reaction, i.e. ${ }^{\mathrm{ANT}}+\mathrm{THEO}^{+} \rightarrow{ }^{\mathrm{S}} \mathrm{ANT}^{+}+$THEO (Fig. 2C). The ${ }^{\mathrm{S}} \mathrm{ANT}^{{ }^{*}}$ spectra were identical when generated using $\mathrm{NAP}^{+}$as oxidant (Fig. S3-S5 in the ESI+). Also note that the spectra of ${ }^{\mathrm{S}} \mathrm{ANT}^{+}$remained unchanged at tenfold higher concentration or at temperatures between 22 ${ }^{\circ} \mathrm{C}$ to $-50{ }^{\circ} \mathrm{C} . \underline{21}$
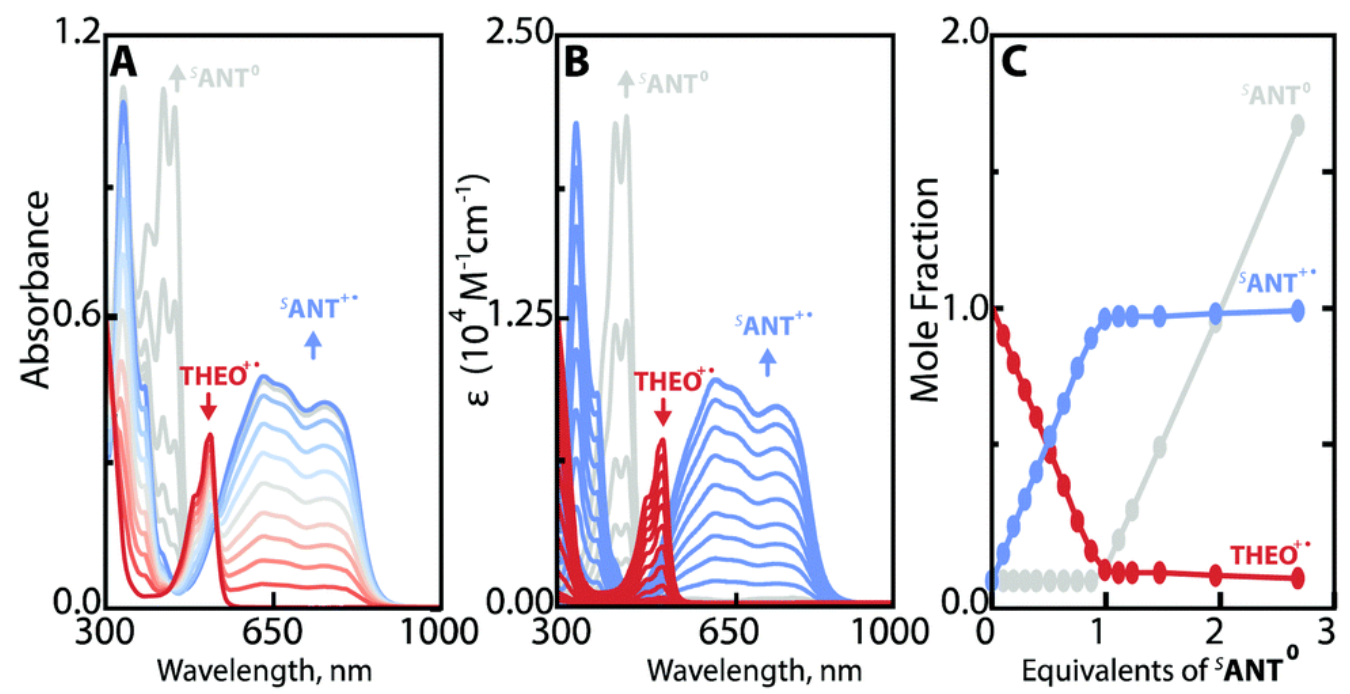

Fig. 2 (A) Spectral changes observed upon the reduction of $0.049 \mathrm{mM} \mathrm{THEO}^{+*}$ in $\mathrm{CH}_{2} \mathrm{Cl}_{2}(3 \mathrm{~mL})$ by addition of $4 \mu \mathrm{L}$ increments of $3.6 \mathrm{mM}$ solution of ${ }^{\mathrm{S}} \mathrm{ANT}$ in $\mathrm{CH}_{2} \mathrm{Cl}_{2}$. (B) Clean deconvolution of each spectrum from figure $\mathbf{A}$ into its component spectra, i.e.THEO ${ }^{+}$(burgundy), ${ }^{S} \mathbf{A N T}^{+}$(blue), and ${ }^{\mathrm{S}} \mathrm{ANT}$ (grey), with negligible residual $(<0.1 \%)$. (C) Plot of the mole fractions of THEO $^{+*}$ (burgundy) and ${ }^{S} \mathbf{A N T}^{+*}$ (blue) against the added equivalents of neutral ${ }^{\mathrm{S}}$ ANT. 
Symbols represent experimental points, while the solid lines show best-fit to experimental points using $\Delta \mathrm{G}_{1}=$ $\mathrm{E}_{\text {red }}\left(\right.$ THEO $\left.^{+*}\right)-\mathrm{E}_{\text {ox }}\left({ }^{\mathrm{S}} \mathrm{ANT}\right)=0.2 \mathrm{~V} .^{\underline{20}}$

The stability of $\left[{ }^{5} \mathrm{ANT}^{+} \mathrm{SbCl}_{6}{ }^{-}\right]$was further attested by its quantitative isolation by precipitation using diethyl ether from a reaction of ${ }^{\mathrm{S}} \mathrm{ANT}(0.25 \mathrm{mmol})$ with $\mathrm{NO}^{+} \mathrm{SbCl}_{6}^{-}(0.25 \mathrm{mmol})$ in $\mathrm{CH}_{2} \mathrm{Cl}_{2}(10 \mathrm{~mL})$ at $0{ }^{\circ} \mathrm{C}$ (see Section S3 in the ESIt for details). The X-ray quality single crystals of $\left[{ }^{\mathrm{S}} \mathrm{ANT}^{+{ }^{+}} \mathrm{SbCl}_{6}{ }^{-}\right]$were obtained by a careful layering of its $\mathrm{CH}_{2} \mathrm{Cl}_{2}$ solution with toluene and storage in a refrigerator $\left(\sim-10^{\circ} \mathrm{C}\right)$ for $48 \mathrm{~h}$. The determination of the precise $\mathrm{X}-$ ray structures of $\left[{ }^{\mathrm{S}} \mathrm{ANT}^{+{ }^{+}} \mathrm{SbCl}_{6}{ }^{-}\right]$as well as of neutral ${ }^{\mathrm{S}} \mathrm{ANT}$ allowed a detailed elucidation of the structural changes induced by $1-\mathrm{e}^{-}$oxidation, which was compared with theory.

The ORTEP diagrams of racemic ${ }^{S} \mathbf{A N T}$ and ${ }^{S} \mathbf{A N T}^{+}$as well as their crystal packing diagrams are compiled in Fig. 3A-D. $¥$ The enantiomers of both neutral and cationic ${ }^{S}$ ANT pack in separate stacks; and the stacks of individual enantiomers of ${ }^{\mathrm{S}} \mathrm{ANT}^{+*}$ and $\mathrm{SbCl}_{6}{ }^{-}$counter ions form mixed layers along the ab plane. No contacts less than the sum of van der Waals radii amongst the ${ }^{\mathrm{S}} \mathbf{A N T}^{+*}$ moieties in its crystals were observed; and the anthracene fragment of both ${ }^{S} \mathbf{A N T}$ and ${ }^{S} \mathbf{A N T}^{+\cdot}$ were significantly distorted from planarity (see Fig. S16 in ESI + ). The dihedral angle between phenyl and anthracene core showed a negligible change $\left(\sim 0.5^{\circ}\right)$ upon $1-\mathrm{e}^{-}$oxidation due to the rigidity of bimethylene bridges. $\underline{16}$

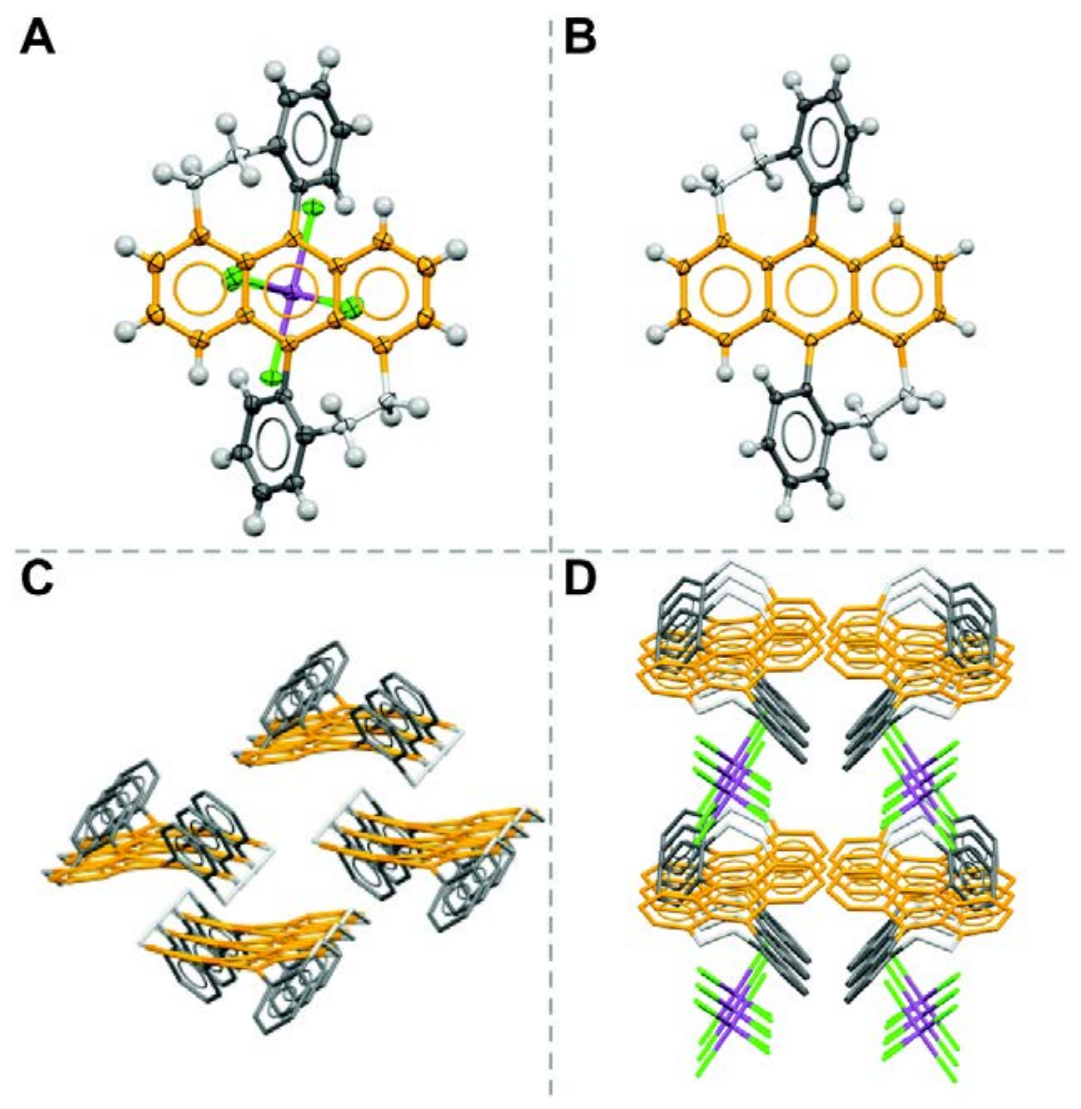

Fig. 3 The ORTEP diagrams (50\% probability) of ${ }^{\mathrm{S}} \mathrm{ANT}(\mathrm{A})$ and $\left[{ }^{\mathrm{S}} \mathrm{ANT}^{+{ }^{+}} \mathrm{SbCl}_{6}{ }^{-}\right]$(B), and the packing diagrams of neutral (C) and cation-radical salt (D) of ${ }^{\mathrm{S}}$ ANT.

A comparison of the bond length changes in the ${ }^{\mathrm{S}} \mathbf{A N T} \rightarrow{ }^{\mathrm{S}} \mathbf{A N T}{ }^{+}$transformation showed that the bond contractions and elongations were mostly confined to the anthracene core, and the 9,10-phenyl groups did not undergo significant changes, suggesting that the spin/charge is largely confined to the anthracene core (Fig. 4). Furthermore, a plot of the bond length changes in $\mathbf{A N T} \rightarrow \mathbf{A N T}^{+*}$ transformation obtained by X-ray crystallography against those obtained by DFT calculations clearly shows a linear correspondence (Fig. 4C). Indeed, the oxidation-induced bond length changes in ${ }^{5} \mathbf{A N T}^{+}$closely followed the disposition of the bonding/antibonding 
lobes of HOMO, i.e. bonds with bonding HOMO lobes undergo elongations, whereas the bonds with antibonding lobes undergo contractions (compare Fig. 4A and C). $\underline{\underline{22}}$

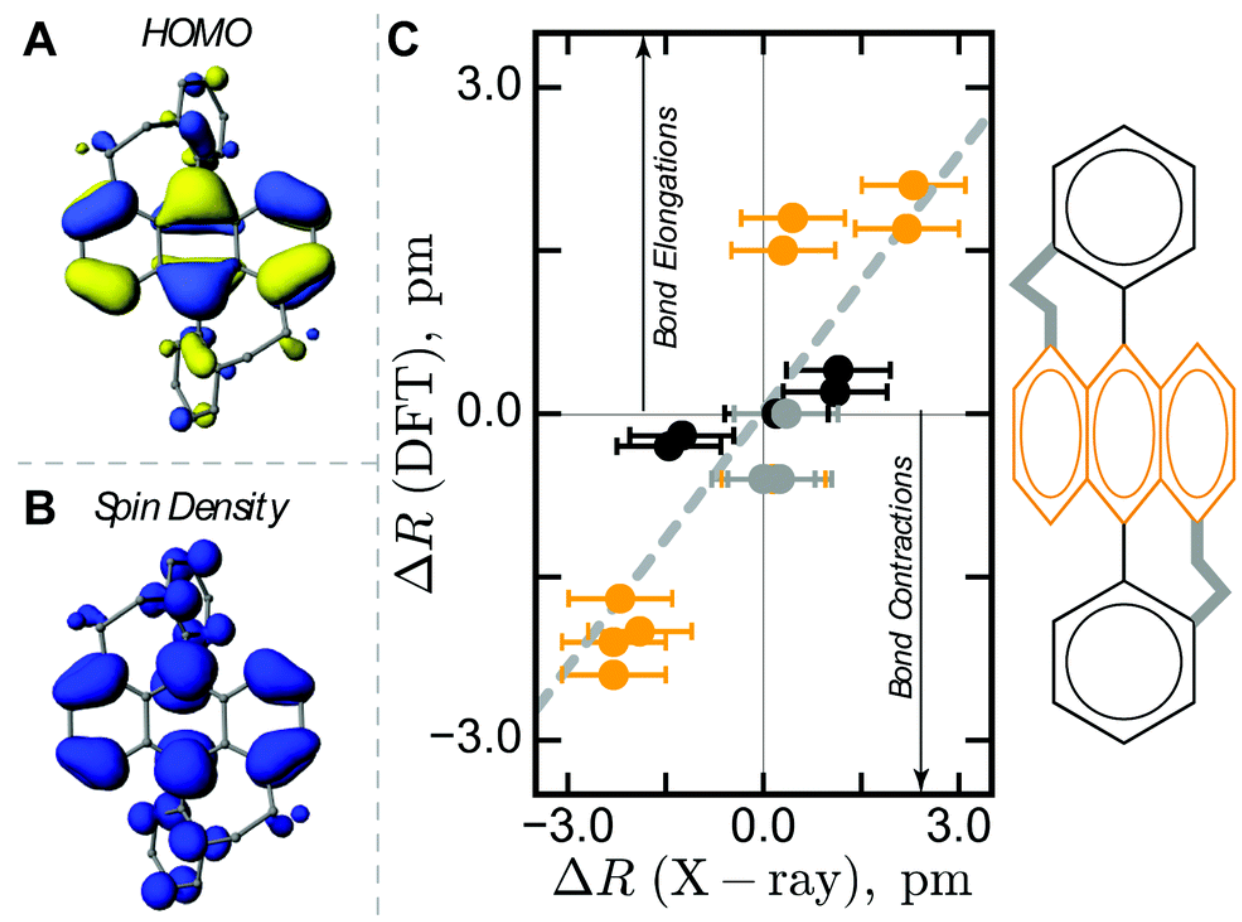

Fig. 4 Isovalue plots of HOMO of neutral ANT (A) and spin density of ANT ${ }^{+*}$ (B) [B1LYP-40/6-

$31 \mathrm{G}(\mathrm{d})+\mathrm{PCM}\left(\mathrm{CH}_{2} \mathrm{Cl}_{2}\right)$ ]. Comparison of the oxidation-induced $\mathrm{C}-\mathrm{C}$ bond length changes in ${ }^{\mathrm{S}} \mathrm{ANT}$ obtained by $\mathrm{X}$-ray crystallography and DFT calculations with a linear trend line $y=0.79 x+0.03, R^{2}=0.71$. Error bars correspond to the standard deviation of the bond length changes $(\sigma=0.8 \mathrm{pm})$. (C) The bond length changes are based on the averages of equivalent bonds.

Building upon this success, we then undertook a detailed conformational analysis at the B1LYP-40/6$31 \mathrm{G}(\mathrm{d})+\mathrm{PCM}\left(\mathrm{CH}_{2} \mathrm{Cl}_{2}\right)$ level of theory to examine why the racemization of ${ }^{\mathrm{S}} \mathrm{ANT}$ occurs at ambient temperatures, despite a relatively high energy barrier. We also examined whether this racemization barrier is altered upon oxidation to cation radical.

A careful search in the conformational space showed that enantiomer of ${ }^{\mathrm{A}} \mathrm{ANT}$ first converts to ${ }^{\mathrm{A}}$ ANT by flipping one of its phenyl rings, while the second remains fixed (Fig. 5, above). This interconversion proceeds through a highly twisted transition state $\left(\Delta \mathrm{G}^{\ddagger}=27.6 \mathrm{kcal} \mathrm{mol}^{-1}, \mathrm{TS} 1\right)$, in which the rotation of a single phenyl group accompanies a significant puckering of anthracene core and prompts an inversion at both bridging methylenes. As the inversion of methylenes and rotation of the phenyl group progresses, the puckering in the anthracene reduces (see superimposed structures in Fig. 5), producing a high-energy intermediate $\left(\Delta \mathrm{G}=12.3 \mathrm{kcal} \mathrm{mol}^{-1}, \mathrm{I}\right)$, which then transforms to achiral ${ }^{A} A N T$ through an almost barrierless process $\left(\Delta \mathrm{G}^{\ddagger}=2.0 \mathrm{kcal} \mathrm{mol}^{-1}, \mathrm{TS2}\right)$. The calculations predict that ${ }^{A}$ ANT lies $2.8 \mathrm{kcal} \mathrm{mol}^{-1}$ higher than ${ }^{\mathrm{S}} \mathrm{ANT}$ (Fig. 5) and the racemization barrier of 27.6 $\mathrm{kcal} \mathrm{mol}^{-1}$ is in fair agreement with the barrier of $22.6 \mathrm{kcal} \mathrm{mol}^{-1}$ obtained by experiment. 8,9 


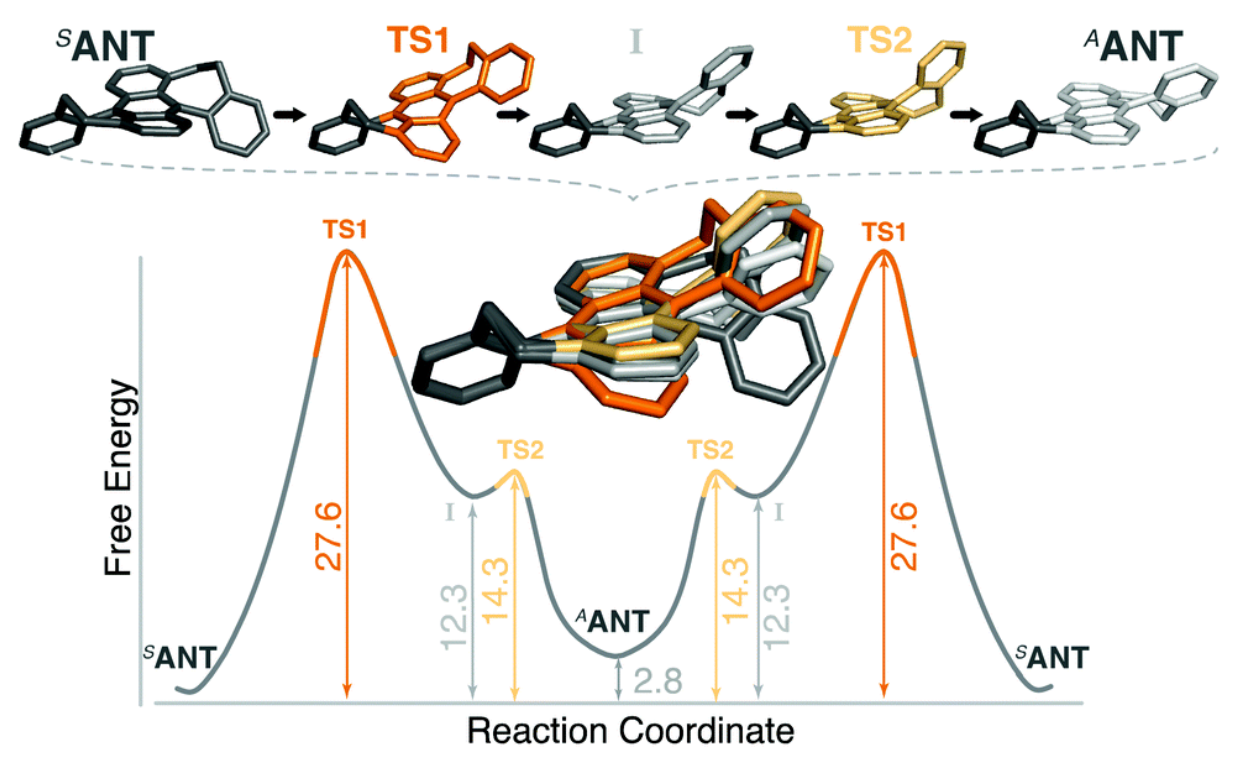

Fig. 5 IRC (Intrinsic reaction coordinate) pathway of the ${ }^{S} A N T(R, R) \rightleftarrows{ }^{S} A N T(S, S)$ racemization and the structures and Gibbs free energies (in kcal mol${ }^{-1}$ ) of transition states (TS1, TS2) and intermediates (I) along the pathway. Superimposed structures ( ${ }^{\mathrm{S}} \mathrm{ANT}, \mathrm{TS1}, \mathbf{I}, \mathbf{T S 2}$ and ${ }^{\mathrm{A}} \mathrm{ANT}$ ) showing the rotation of single phenyl group during ${ }^{\mathrm{S}} \mathrm{ANT}$ $\rightarrow{ }^{\mathrm{A} A N T}$ transformation.

Interestingly, racemization of a model compound $(\mathbf{M})$ containing only one bridged phenyl group follows an uncannily similar pathway with a similar activation barrier of $24.5 \mathrm{kcal} \mathrm{mol}^{-1}$ (Fig. S6 in the ESI+), signifying that the second phenyl group is not involved in the ${ }^{S}$ ANT $\rightleftarrows{ }^{A}$ ANT interconversion. However, once the meso ${ }^{A}$ ANT is formed, the flipping of the second phenyl ring via an identical mirror-imaged pathway completes the conversion of original ${ }^{\mathrm{S}}$ ANT into its enantiomer. Thus, the racemization of ${ }^{\mathrm{S}} \mathrm{ANT}$ proceeds via achiral ${ }^{\mathrm{A}} \mathrm{ANT}$ as an intermediate, i.e.eqn (2).

(2)

${ }^{\mathrm{S} A N T}(\mathrm{R}, \mathrm{R}) \rightleftarrows{ }^{\mathrm{A} A N T}$ (meso) $\rightleftarrows{ }^{\mathrm{S} A N T}(\mathrm{~S}, \mathrm{~S})$

Racemization of neutral and cation radical of ${ }^{S}$ ANT follows identical pathways, and their activation barriers differ only by $1.2 \mathrm{kcal} \mathrm{mol}^{-1}$ (see Fig. S7 in the ESI+), suggesting that the structural changes in ${ }^{\mathrm{S}} \mathrm{ANT}^{+{ }^{*}}$ induced by $1-\mathrm{e}^{-}$ oxidation have a little impact on the conformational switching. Also, the energy difference between ${ }^{\mathrm{S}} \mathrm{ANT}^{+{ }^{*}}$ and ${ }^{A} \mathrm{ANT}^{+}$of $2.2 \mathrm{kcal} \mathrm{mol}^{-1}$ is similar to that observed in the neutral analogues (i.e. $2.8 \mathrm{kcal} \mathrm{mol}^{-1}$ ).

Despite a high estimated racemization barrier $\left(22.6 \mathrm{kcal} \mathrm{mol}^{-1}\right)$, the enantiopure ${ }^{\mathrm{S}} \mathrm{ANT}$ undergoes racemization with a half-life (i.e. $t_{1 / 2}$ ) of 1.1 hours at ambient temperatures, as determined using the Eyring equation (see Section S5 in the ESI + ). ${ }^{-}$As the reaction half-life exponentially depends on the activation barrier, the rate of racemization can be controlled or even halted by increasing the activation barrier. In order to assess the necessary increase of the activation barrier required to prevent racemization, we performed a kinetic analysis of ${ }^{S} A N T(R, R) \rightleftarrows{ }^{S} A N T(S, S)$ interconversion process.

Simulated time-evolutions for the formation of racemic mixture of ${ }^{S} A N T(R, R) /{ }^{S} A N T(S, S)$ from pure $(m e s o)^{A} A N T$ or enantiopure ${ }^{S}$ ANT was obtained from numerical solution of the system of the first-order reactions from eqn (2) (see Section S5 in the ESI+). The simulations predict that ${ }^{A} A N T$ quickly converts into equal amounts of ${ }^{S} A N T(R, R)$ and ${ }^{S} A N T(S, S)$ with the reaction half-life of $\sim 20$ seconds (Fig. $6 A$ ), while the enantiopure ${ }^{S}$ ANT has a reaction half-life of 1.1 hours (Fig. 6B). 

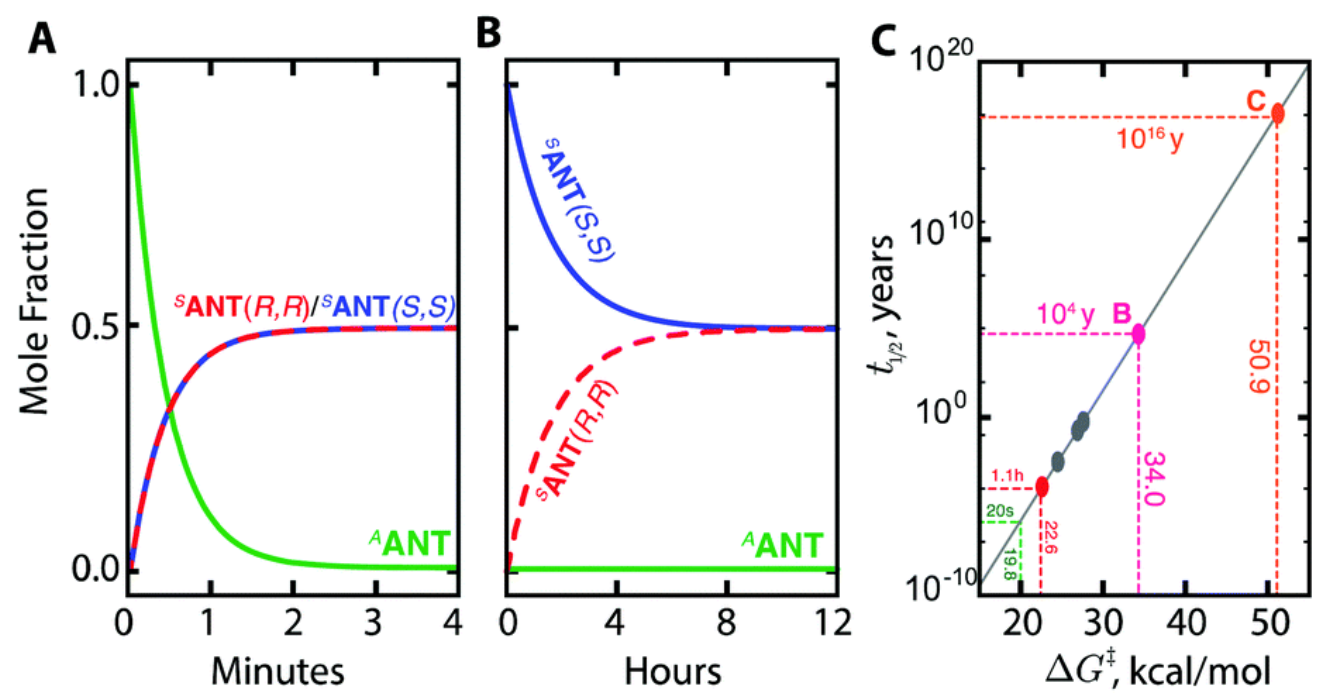

Fig. 6 Simulated mole fraction plots of ${ }^{S} A N T(R, R),{ }^{S} A N T(S, S)$ and ${ }^{A} A N T$ with respect to time with initially $(A)$ only (meso) ${ }^{A} A N T$ and (B) enantiopure ${ }^{S} A N T$ using $\Delta G^{\ddagger}=22.6 \mathrm{kcal} \mathrm{mol}^{-1}$. (C) Plot of the racemization reaction half-lives $\left(t_{1 / 2}\right)$ against the activation barrier $\left(\Delta G^{\ddagger}\right)$ from Table 1 . Note that kinetic simulations in (A) and (B) show little difference on the racemization half-lives when the high-energy intermediate $(\mathrm{I})$ is included in the kinetic analysis and can therefore be excluded for sake of simplicity (see Fig. S15 in the ESI†).

The two-order of magnitude difference in half-lives (compare Fig. 6A and B), dependent on the starting reactant, cannot be simply accounted for by the presence of two reaction channels in case of ${ }^{A}$ ANT, i.e. ${ }^{\mathrm{S} A N T}(\mathrm{R}, \mathrm{R}) \leftarrow{ }^{\mathrm{A}}$ ANT $\rightarrow{ }^{S} \mathrm{ANT}(\mathrm{S}, \mathrm{S})$, as it accounts only for an increase by a factor of 2 . Rather, the energy difference of $2.8 \mathrm{kcal} \mathrm{mol}^{-1}$ between ${ }^{\mathrm{S}} \mathbf{A N T}$ and ${ }^{\mathrm{A}} \mathbf{A N T}$ contributes to lowering of the activation barrier for ${ }^{\mathrm{A}} \mathrm{ANT} \rightarrow{ }^{\mathrm{S}} \mathrm{ANT}$ transformation and is largely responsible for the reduced half-life (Fig. 6C). Interestingly, a simple inspection of Fig. $6 \mathrm{C}$ suggests that the doubling of the activation barrier for ${ }^{S}$ ANT $\rightarrow{ }^{A}$ ANT transformation $\left(22.6 \mathrm{kcal} \mathrm{mol}^{-1}\right)$ would increase the racemization half-life by a factor of $10^{16}$ (Fig. 6C). As the ${ }^{S} A N T(R, R) \rightleftarrows{ }^{S} A N T(S, S)$ interconversion requires a rotation of the phenyl rings, this can be most effectively impeded by placing a substituent at the ortho position of phenyl groups, i.e. the boxed structure in Fig. 7.

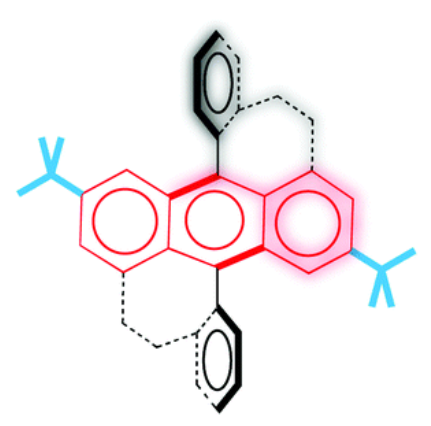

A

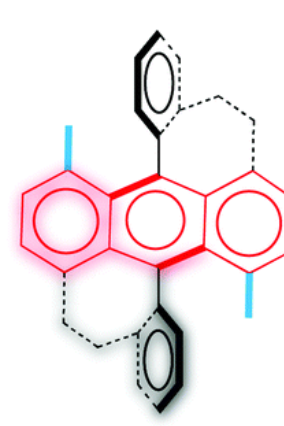

B

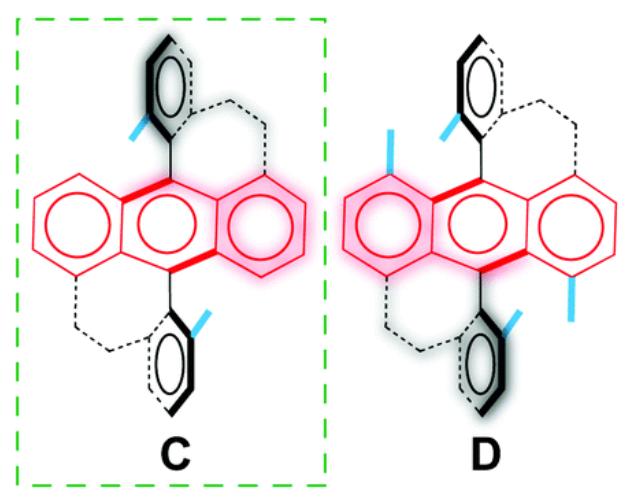

Fig. 7 Structure of four derivatives of ${ }^{S}$ ANT.

Consistent with this expectation, calculated racemization barriers for various methyl substituted (B, C, D) ${ }^{\text {SANT }}$ derivatives (Table 1 ) shows that the substitution on the phenyl rings (i.e.C) produces a much higher activation barrier $\left(51 \mathrm{kcal} \mathrm{mol}^{-1}\right)$ than when the substitution is on anthracene core (B, $\left.34 \mathrm{kcal} \mathrm{mol}^{-1}\right)$.

Table 1 Computed activation energies of racemization $\left(\Delta \mathrm{G}^{\ddagger}, \mathrm{kcal} \mathrm{mol}^{-1}\right)$, energy difference between ${ }^{\mathrm{S}} \mathrm{ANT}$ and ${ }^{\mathrm{A}} \mathrm{ANT}$ conformations $\left(\Delta \mathrm{G}_{\mathrm{anti}}, \mathrm{kcal} \mathrm{mol}{ }^{-1}\right)$ and racemization half-lives $\left(\mathrm{t}_{1 / 2}\right)$ of ${ }^{\mathrm{S}} \mathrm{ANT}$ derivatives. All ${ }^{\mathrm{S}} \mathrm{ANT}$ derivatives 
follow a racemization pathway similar to that of parent ${ }^{S}$ ANT (Fig. S6-S11 in the ESI). See Table S16 in ESI for racemization half-lives scaled to reproduce experimentally observed half-live of ${ }^{\mathrm{S}}$ ANT

\begin{tabular}{|c|c|c|c|c|c|c|}
\hline & Neutral & & & $\begin{array}{l}\text { Cation } \\
\text { radical }\end{array}$ & & \\
\hline & $\Delta \mathbf{G}^{\ddagger}$ & $\Delta \mathbf{G}_{\text {anti }}$ & $t_{1 / 2}$ & $\Delta \mathbf{G}$ & $\Delta \mathbf{G}_{\text {anti }}$ & $t_{1 / 2}$ \\
\hline${ }^{\mathrm{s}} \mathrm{ANT}(\exp )^{9}$ & 22.6 & $\mathrm{n} / \mathrm{a}$ & $1.1 \mathrm{~h}$ & $\mathrm{n} / \mathrm{a}$ & $\mathrm{n} / \mathrm{a}$ & $\mathrm{n} / \mathrm{a}$ \\
\hline${ }^{s}$ ANT & 27.6 & 2.8 & $5.3 \times 10^{3} \mathrm{~h}$ & 26.4 & 2.4 & $696 \mathrm{~h}$ \\
\hline $\mathrm{M}$ & 24.5 & 0.0 & $28 \mathrm{~h}$ & 22.8 & 0.0 & $1.6 \mathrm{~h}$ \\
\hline$A$ & 26.9 & 2.5 & $1.6 \times 10^{3} \mathrm{~h}$ & 26 & 2.1 & $354 \mathrm{~h}$ \\
\hline B & 34.3 & 3.1 & $4.9 \times 10^{4}$ year & 34 & 2.4 & $3.0 \times 10^{4}$ year \\
\hline C & 51.2 & 4.1 & $1.2 \times 10^{17}$ year & 42.2 & 3.0 & $3.0 \times 10^{10}$ year \\
\hline D & 56.7 & 2.6 & $1.3 \times 10^{21}$ year & 50.9 & 1.0 & $7.2 \times 10^{16}$ year \\
\hline
\end{tabular}

Examination of the $\mathbf{B}$ and $\mathbf{C}$ transition state structures reveals the considerable structural distortion required for the methyl substituted rings (i.e. anthracene core in case of $\mathbf{B}$ and phenyl group in case of $\mathbf{C}$ ) during the rotation of the phenyl group (see Fig. S12 in the ESI†). It is well known that the energy needed to distort PAHs such as anthracene is rather modest as compared to the distortion of a single aromatic ring. ${ }^{23}$ Indeed, methyl substitutions both at phenyl groups and anthracene (i.e.D) increases the barrier minimally $\left(57 \mathrm{kcal} \mathrm{mol}^{-1}\right)$ as compared to $\mathbf{C}\left(51 \mathrm{kcal} \mathrm{mol}^{-1}\right)$. Note also that substitution of ${ }^{\mathrm{S}} \mathrm{ANT}$ by remote t-butyl substituents $(\mathbf{A})$ does not affect the activation barrier $\left(27 \mathrm{kcal} \mathrm{mol}^{-1}\right)$.

Although the SANT derivatives B or C or $\mathbf{D}$ have sufficiently large racemization barriers to halt racemization on a practical timescale (Table 1), structure $\mathbf{C}$ is the most viable candidate for synthetic pursuit rather than $\mathbf{B}$ and $\mathbf{D}$ because the peri substitution of anthracene core raises the energies of $\mathbf{B}$ and $\mathbf{D}$ by $11 \mathrm{kcal} \mathrm{mol}^{-1}$ as compared to C owing to the steric crowding (see Fig. S13 in the ESIt).

In conclusion, we have shown that the SANT scaffold is well suited for the formation of a stable cation radical, by isolation and structural characterization via X-ray crystallography. Unfortunately, ${ }^{\mathrm{S} A N T}$ racemizes with the half life of $\sim 1$ hour. A systematic conformational and kinetic analysis of the racemization pathway led us to identify a

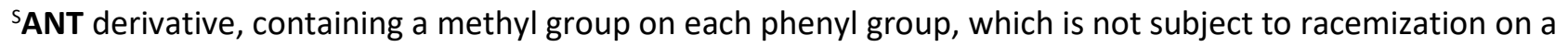
practical timescale. Efforts are underway for the preparation of this minimally altered ${ }^{\mathrm{S}} \mathrm{ANT}$ derivative for the isolation and study of a new class of enantiopure cation radicals.

We thank the NSF (CHE-1508677) and NIH (R01-HL112639-04) for financial support and Dr Sergey V. Lindeman for X-ray crystallography and Ms A. Boddeda for assistance with redox titrations. The calculations were performed on the high-performance computing cluster Père at Marquette University.

\section{Notes and references}

1. T. P. Yoon, M. A. Ischay and J. Du, Nat. Chem., 2010, 2, 527.

2. T. Mori and Y. Inoue, J. Phys. Chem. A, 2005, 109, 2728.

3. G. L. Rikken, J. Fölling and P. Wyder, Phys. Rev. Lett., 2001, 87, 236602.

4. F. Pop, P. Auban-Senzier, E. Canadell, G. L. J. A. Rikken and N. Avarvari, Nat. Commun., 2014, 5, 3757.

5. C. Réthoré, N. Avarvari, E. Canadell, P. Auban-Senzier and M. Fourmigué, J. Am. Chem. Soc., 2005, 127, 5748.

6. S. Yang, F. Pop, C. Melan, A. C. Brooks, L. Martin, P. Horton, P. Auban-Senzier, G. L. Rikken, N. Avarvari and J. D. Wallis, CrystEngComm, 2014, 16, 3906.

7. T. J. Müller and U. H. Bunz, Functional organic materials: syntheses, strategies and applications, John Wiley \& Sons, 2007.

8. I. Agranat, S. Cohen, R. Isaksson, J. Sandstroem and M. R. Suissa, J. Org. Chem., 1990, 55, 4943. 
9. I. Agranat, M. R. Suissa, S. Cohen, R. Isaksson, J. Sandström, J. Dale and D. Grace, Chem. Commun., 1987, 381.

10. M. Banerjee, S. V. Lindeman and R. Rathore, J. Am. Chem. Soc., 2007, 129, 8070.

11. M. R. Talipov, T. S. Navale and R. Rathore, Angew. Chem., Int. Ed., 2015, 54, 14468.

12. R. Shukla, S. H. Wadumethrige, S. V. Lindeman and R. Rathore, Org. Lett., 2008, 10, 3587.

13. V. J. Chebny, R. Shukla, S. V. Lindeman and R. Rathore, Org. Lett., 2009, 11, 1939.

14. T. S. Navale, L. Zhai, S. V. Lindeman and R. Rathore, Chem. Commun., 2009, 2857.

15. D. Wang, M. R. Talipov, M. V. Ivanov and R. Rathore, J. Am. Chem. Soc., 2016, 138, 16337.

16. Note that relatively higher oxidation potential of 9,10-diphenylanthracene (DPA) as to ${ }^{\mathrm{S}}$ ANT arises from the larger phenyl-anthracene dihedral angle in DPA, as opposed to ${ }^{\mathrm{S}} \mathrm{ANT}$ owing to the ethane bridge $\left(\sim 65^{\circ}\right.$ vs. $\left.35^{\circ}\right)$.

17. R. Rathore, C. L. Burns and M. I. Deselnicu, Org. Synth., 2005, 1.

18. R. Rathore, C. L. Burns and M. I. Deselnicu, Org. Lett., 2001, 3, 2887.

19. R. Rathore and J. K. Kochi, Acta Chem. Scand., 1998, 52, 114.

20. M. R. Talipov, A. Boddeda, M. M. Hossain and R. Rathore, J. Phys. Org. Chem., 2015, $29,227$.

21. Owing to the steric crowding, ${ }^{S} \mathrm{ANT}^{+\cdot}$ did not show formation of dimeric cation radical even in the presence large excess of ${ }^{\mathrm{S}} \mathrm{ANT}{ }^{0}$.

22. M. R. Talipov, A. Boddeda, S. V. Lindeman and R. Rathore, J. Phys. Chem. Lett., 2015, 6, 3373.

23. R. A. Pascal, Chem. Rev., 2006, 106, 4809.

† Electronic supplementary information (ESI) available: Full experimental details for ${ }^{\mathrm{S}} \mathbf{A N T}$ and $\left[{ }^{\mathrm{S}} \mathbf{A N T}^{+{ }^{*}} \mathrm{SbCl}_{6}{ }^{-}\right]$ and computational details. CCDC 1525472 and 1525473. For ESI and crystallographic data in CIF or other electronic format see DOI: $10.1039 / \mathrm{c} 6 \mathrm{cc} 10307 \mathrm{c}$

¥ Crystal structure data for SANT [C30H22] (raj25q): FW = 382.48, P21/c, a = 7.64722(7) $\AA, b=10.95523(14)$ $\AA, c=22.9991(3) \AA, \beta=94.4658(10)^{\circ}, Z=4, V=1920.95(4) \AA ̊ 3, D=1.323 \mathrm{~g} \mathrm{~cm}-3, T=100 \mathrm{~K}, 3895$ reflections measured, 3466 unique reflections, Rint $=0.0259,271$ parameters refined, $R($ all $)=0.0370, w R($ all $)=0.0975$, $\mathrm{S}=1.045$ (CCDC 1525472). Crystal structure data for [SANT+'SbCl6-] [C3OH22 SbCl6] (raj25s): $\mathrm{FW}=716.93$,

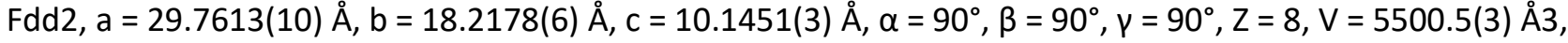
$\mathrm{d}=1.731 \mathrm{~g} \mathrm{~cm}-3, \mathrm{~T}=100 \mathrm{~K}, 2540$ reflections measured, 2368 unique reflections, Rint $=0.0794,168$ parameters refined, $\mathrm{R}(\mathrm{all})=0.0389, \mathrm{wR}(\mathrm{all})=0.0966, \mathrm{~S}=1.046(\mathrm{CCDC} 1525473)$. 